\title{
The Effect of the Ultrasonic Energy on Dyeing a Polyamide Material with Reactive Dyes, Including a Different Chromophore and a Reactive Group
}

\author{
Nigar Merdan ${ }^{1}$, Seyda Canbolat ${ }^{1}$, Mehmet Kılınc ${ }^{1}$, Filiz Akın² \\ ${ }^{1}$ Istanbul Commerce University, Faculty of Engineering and Design, Department of Fashion and Textile, Istanbul, Turkey. \\ ${ }^{2}$ Abant Izzet Baysal University, Vocational High School, Bolu, Turkey
}

\begin{abstract}
In this study, reactive dyes having different chromophore and reactive groups were used to dye polyamide fabric such as C.I. Reactive Blue 4 (Basilen Blue MR-BASF-chromophore group of anthraquinone, a reactive dye in the structure of dichlorotriazinel), C.I. Reactive Blue 15 (Cibacron Turquoise GF-CGY-chromophore group of phtalocyanine, a reactive dye in the structure of monochlorotriazinel),C.I. Reactive Blue 52 (Drimarene Blue X3LR-S-chromophore group of disazo-formazon metal complex, a reactive dye in the structure of trichloroprimidin) and C.I. Reactive Blue 69 (Lanasol Blue 3G-CGy-chromophore group of, - boromoacrylamide of reactive group). The samples were dyed with conventional and ultrasonic method. After the dyeing process, the dye exhaustion rate, dye remova after washing, $\%$ fixation values were compared in terms of the methods. Besides, the washing, light, rubbing and perspiration fastness values and $\Delta \mathrm{E}^{*}$, $\Delta \mathrm{L}^{*}, \Delta \mathrm{a}^{*}$ and $\Delta \mathrm{b}^{*}$ values were analysed in terms of type of reactive dye and dyeing method.
\end{abstract}

Keywords: Ultrasonic, Conventional, Kinetic of Dyeing, Polyamide Fabric.

\section{INTRODUCTION}

Ultrasonic sound waves have frequencies that cannot be reached by a human and a human ear can hear the sound waves between $16 \mathrm{~Hz}-16 \mathrm{kHz}$, whereas the ultrasonic sound waves have the frequency between $20 \mathrm{kHz}-20 \mathrm{MHz}$. The strength of the ultrasonic energy makes his chemical effect occur through cavitation incident. Like a sound wave, ultrasonic energy is transmitted via waves. When the sufficient amount of a negative pressure is implemented on the liquid, fission is observed in the liquid and cavitation ballonets appear. In the successive compressing periods, these ballonets cause a huge among of energy to occur as they are colliding to each other [1]. The use of ultrasonic energy in the textile processes contributes in the aspects of the duration of process, save of energy and chemicals and the improvement of the product quality. As the result of the cavitation, occurring between solid/liquid intermediary surfaces, the increase in the mass transfer from liquid to solid occur [2]. The homogenization in the bath and ultrasonic pressure distribution, the position of transducers, the form of fabric's passing through the machine, the temperature of the bath are remarked for the use of ultrasonic energy in the industrial dimension [3].

In the last washings of the reactive dyeing, these are found that washing fastness develops in the method in which the ultrasonic probe is used [4]. Sonication is positive effect on the cellulosic fibre being dyed by the reactive dyes and in terms of fastness features, $[5,6]$ in the disperse dye as well as the PES dyeing, sonication does not have any effect on the fibre's Tg value, dyeing exhaustion rate [7]. In reactive dyes PA and PA/lycra mixture material's being dyed, there is a dye adsorption, yet there is not an effect on the fastness features of the dyeing [8-9]. In the dyeing of Nylon 6 with the reactive dyes, the colour strength of the dyeing increase, the diffusion is better in the dyes due to the de-aggregation in the dyes molecules and the ultrasonic energy can be more effective on the dyeing - fibre covalent bond fixation [8].

Reactive dyes have different reactivity features because of the reactive groups that they carry. Depending on the chromophore group of the dyes, substantial features must be different. Reactive dyes including a triazine ring create a covalent bond with the - $\mathrm{OH}$ groups in the cellulose through substitution. The sulphateethylsulphone reactive group's reactive dyes, used in this study, turn into vinylsulphone group, having high reactivity, and create an ether bond with the fiber. Bifunctional reactive dyes, including a Vinylsulphone-monochlorotriazine structure, are bonded with the functional groups of the cellulosic fibre so as to create a covalent bond regarding to both the nucleophilic

Corresponding Author: Nigar MERDAN, Tel: +90 (212) 4440 413, E-mail: nmerdan@ticaret.edu.tr

Submitted: 15 October 2014, Revised: 04 March 2015, Accepted: 01 July 2015 
substitution and the addition mechanisms. These reactive groups in the dyes molecules are effective on the reaction speed of dyeing, stability of the bond between the fibre dyes and the dyeing fastness [9-10].

In this study, the polyamide fabric was dyed with different reactive dyes via conventional and ultrasonic methods. After the dyeing process, the fastness and color properties of samples were evaluated in terms of reactive dyes and dyeing method. According to the results, the ultrasonic method caused to decrease the use of energy and water. Furthermore, ultrasonic energy caused to decrease the duration of dyeing process.

\section{MATERIAL AND METHOD}

In this study, C.I. Reactive Blue 4 (Basilen Blue MR-BASFanthraquinone of chromophore group, a reactive dye in the structure of reactive group's dichlorotriazinel), C.I. Reactive Blue 15 (Cibacron Turquoise GF-CGy-Phthalocyanine of chromophore group, a reactive dyes in the structure of a reactive group's monochlorotriazinel), C.I. Reactive Blue 52 (Drimarene Blue X3LR-S- disazo of chromofor group - formazon metal complex, a reactive dye in the structure of trichloroprimidin reactive group) and C.I. Reactive Blue 69 (Lanasol Blue 3G-CGy-anthraquinone of chromophore group, a reactive dye in the structure of - boromoacrylamide reactive group) four commercial reactive dyes were used without purification.

\subsection{Material}

In this study, the polyamide fabric woven as plain weave from texture yarn was used. The weight of fabric is $105 \mathrm{~g} /$ $\mathrm{m}^{2}$. The warp and weft densities are 10 warp/ $\mathrm{cm}$ and 12 weft/ $\mathrm{cm}$, respectively.

\subsection{Devices}

In the measurements, Schimadzu UV-1200 UVspectrophotometer of a visible area, Sonifier 250 (Branson) ultrasonic prob and Colorgen color measurement device were used to investigate the properties of samples.

\subsection{Method}

\subsubsection{Spectrometric Measurements}

The spectrophotometric measurements were carried out with a Schimadzu UV-1200 UV spectrophotometer of a visible area. Primarily, the maximum absorbance value ( max) of the dye was determined. Later, the absorbents values, done by the dye solution's in very diluted concentrations at the max of the dye, were measured. From the yield values, the calibration (concentration-absorbance) line in max of dye was found by means of the "least squares method" [11].

In order to determine the max values of the dye, firstly $1 \mathrm{~g} / \mathrm{l}$ of the stock dye solutions were prepared and 0.01 $\mathrm{g} / \mathrm{l}, 0.02 \mathrm{~g} / 1$ and $0.04 \mathrm{~g} / 1$ stock dye solutions sensitively obtained as these stock solutions were diluted in $100 \mathrm{ml}$ of volumetric flasks. As the distilled water used in the preparation of the solutions were accepted to be a blind bath, spectrophotometric measurements between 380$700 \mathrm{~nm}$ were done. max values belonged to both the dyes were determined from the wavelength-absorbance graphics obtained from these measurements. The ones whose dyeing kinetics were examined in the study: $\max =598 \mathrm{~nm}$ for C.I. Reactive Blue 4, $\max =572 \mathrm{~nm}$ for C.I. Reactive Blue 15 and $\max =618 \mathrm{~nm}$ for C.I. Reactive Blue 52 and $\max =$ $603 \mathrm{~nm}$ for C.I. Reactive Blue 69 (Image 1).
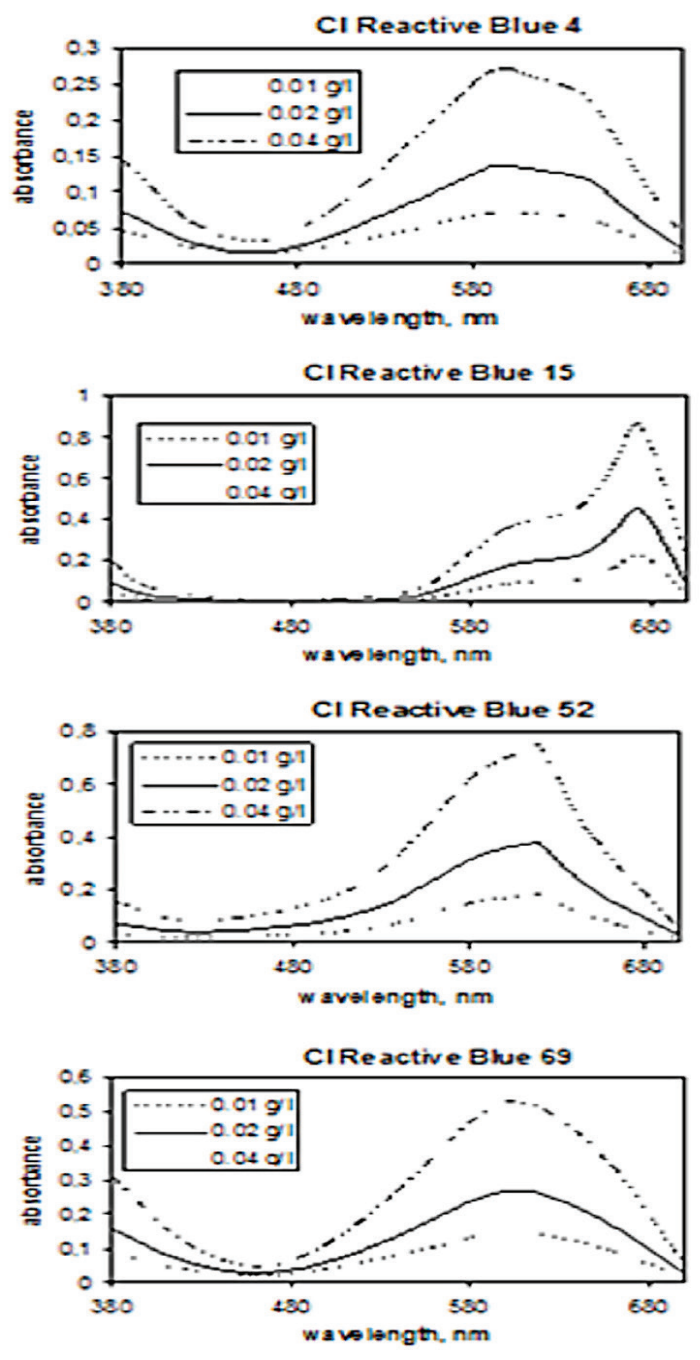

Figure 1. Curves of wavelength and absorbance 
In order to obtain the calibration lines of the dyes, 0.001, $0.002,0.004,0.008,0.01,0.015,0.02$ and $0.04 \mathrm{~g} / 1$ of more diluted dye solutions were prepared from the $1 \mathrm{~g} / 1$ stock dye solutions and the absorbance values were obtained from spectrophotometric measurements in $598 \mathrm{~nm}$ for C.I. Reactive Blue 4, $572 \mathrm{~nm}$ for C.I. Reactive Blue 15, $618 \mathrm{~nm}$ for Reactive Blue 52 and $603 \mathrm{~nm}$ for C.I. Reactive Blue 69.
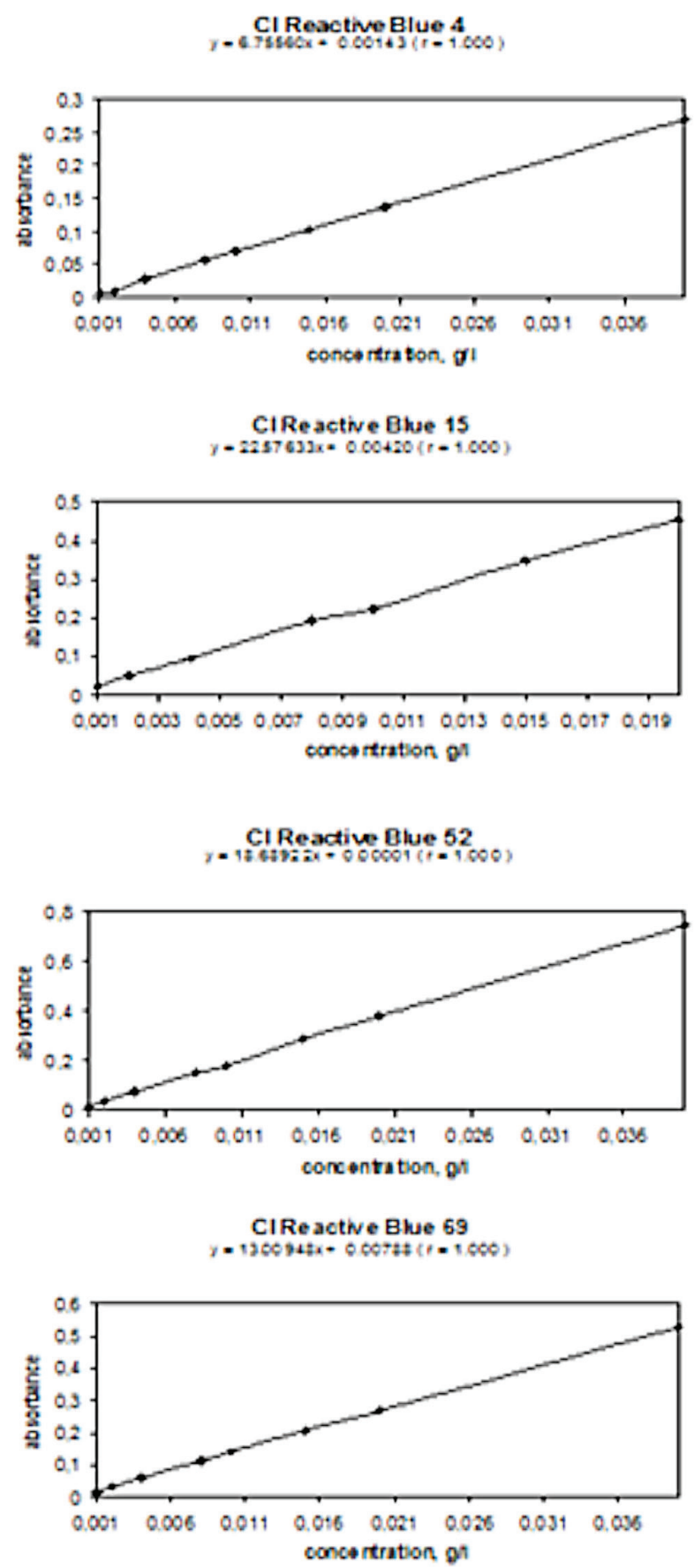

Figure 2. Absorbance and concentration curve

\subsubsection{Dyeing}

Sonifier 250 (Branson) ultrasonic probe was used as the sonication resource in the dyeing processes in which ultrasonic energy was used. The devices' "output control" setting was adjusted to "4" and probe tip of was used. During the dyeing processes the devices' "duty cycle" setting was kept in "hold" and the process was done as the probe tip was dived for $1 \mathrm{~cm}$ inside the dyeing solution. The sonication strength decreases during the operation above the temperatures of $80^{\circ} \mathrm{C}$ with the ultrasonic prob. In the practiced pre-tests, it was determined that the repetition of the dyeing was provided only in the long solution proportions [12]. Due to this reason, the maximum dyeing temperature was taken to be $70^{\circ} \mathrm{C}$, and solution proportion was taken to be 1:600, in the study. In all dyeing processes, the material weight was taken to be $1.5 \mathrm{~g}$.

The microfiber material was used in accordance with dyeing condition, given in the Table 1, with both the conventional and ultrasonic methods. The dyeing was initiated at $40^{\circ} \mathrm{C}$, and after 10 minutes, the solution's temperature was increased to $70^{\circ} \mathrm{C}$ in 20 minutes. After 20 minutes at this temperature, $\mathrm{pH}$ value of solution was brought to the 5.5 with the acetic acid, and it was worked for another 20 minutes at this temperature. The implemented dyeing conditions after the dyeing take place in Table 2.

Table 1. Dyeing Condition

\begin{tabular}{ll}
\hline Bath Ratio: & $1: 600$ \\
Sodium sulphate calsined: & $40 \mathrm{~g} / 1$ \\
Dye: & $\% 1$ \\
$\mathrm{pH}:$ & 5.5 (with acetic acid) \\
Duration: & 70 minutes \\
\hline
\end{tabular}

Apart from the $\mathrm{pH}$ setting, all substances are put into in the beginning of the dyeing.

Table 2. Washing Condition

\begin{tabular}{|c|c|c|c|c|}
\hline & ${ }^{\circ} \mathrm{C}$ & $t(\min )$ & Solution of washing & $\begin{array}{l}\text { Amount of } \\
\text { Solution }\end{array}$ \\
\hline 1. washing & 30 & 10 & Distilled water & $75 \mathrm{ml}$ \\
\hline \multirow[t]{2}{*}{ 2. washing } & 70 & 10 & $\begin{array}{l}\text { 1g/1 Foryl } 100 \text { (Turk - } \\
\text { Henkel) }\end{array}$ & $75 \mathrm{ml}$ \\
\hline & & & $\begin{array}{l}\text { - washing material in non- } \\
\text { ionic structure - }\end{array}$ & \\
\hline
\end{tabular}




\subsubsection{The Dye Exhaustion Rate and the Amount of Removal} Dye in the Washing Process

When duration and $\%$ dye exhaustion curves were determined, the samples of $5 \mathrm{ml}$ were taken from the dyeing solution since the beginning of the dyeing at the 0th, 10th, 20th, 30th, 40th, 50th, 60th and 70th minutes and the absorbance values were found by doing the spectrophotometric measurements of these samples. By using the absorbance values in the calibration equation, the dye concentrations in the solution were found at the above-stated minutes of the dyeing, by the help of these values, $\%$ dye exhaustion rates were calculated (Formula 1).

$\%$ Dye exhaustion rate $=[(\mathrm{c} 1-\mathrm{c} 2) / \mathrm{c} 1] \times 100$

$\mathrm{c} 1=$ Concentration of the initiation, $\mathrm{g} / \mathrm{l}$

$\mathrm{c} 2=$ Concentration at the $\mathrm{x}$. minute of the dyeing, $\mathrm{g} / \mathrm{l}$

The amount of the dye in the washing processes after the dyeing as well as the dye amount transferred to the washing solutions were calculated according to Formula 2.

The amount of the dye in the washing solution

$(\mathrm{g})=(\mathrm{c} \mathrm{x} \mathrm{V}) / 1000$

$\mathrm{V}$ : capacity of the solution of dyeing $\mathrm{ml}$

c: concentration of the dye in the washing solution, $g / 1$

\subsubsection{Fastness of the Dyeing}

In the light fastness test of the dyeing TS 1008, in the washing fastness TS 716, in the rubbing fastness TS 717 and in the perspiration fastness TS 398 standards were used. In the evaluations of light fastness, blue scale, in the other fastness grey scale were used.

\subsubsection{Color Measurements}

The measurements of the \% reflectance values of the dyed samples were done with a Colorgen color measurement device as well as the Dyematch computer program. The samples obtained by the conventional methods in the measurements were accepted to be standard and D/65 light resource was used under $10^{\circ}$ angles. According to the CIELab system, Formula 6 was used in the calculation of the color values [13].

$\Delta \mathrm{E}^{*}=\left[\left(\Delta \mathrm{L}^{*}\right) 2+\left(\Delta \mathrm{a}^{*}\right) 2+\left(\Delta \mathrm{b}^{*}\right) 2\right] 1 / 2$

The $\mathrm{DE}^{*}$ value of the samples is an expression of the color difference. If $\mathrm{DE}^{*}<1$, the difference between two colours is too low; if $\mathrm{DE}^{*}>1$, it is too high. $\mathrm{DL}^{*}$ value's being (-) shows that the sample is too dark for the standard, and being
$(+)$ shows that it is more bright. As a* value increases, the colour turns in to red, when it decreases, into green, when $b^{*}$ value increases the colour turns into yellow, and when it decreases, into blue.

\section{RESULTS AND DISCUSSION}

\subsection{The Dye Exhaustion Rate and Fixation}

The dye exhaustion rate of samples is given in Figure 3. When the dye exhaustion rate of ultrasonic method was compared to the dye exhaustion rate of conventional method; $11.2 \%$ more for C.I. Reactive Blue 4, 51\% more for C.I. Reactive Blue 15, 2.6\% more for C.I. Reactive Blue 52 and $0.4 \%$ more for C.I. Reactive Blue 69 ( Figure 3 ).

Figure 4 shows that the amount of dye transferred to the washing solution and the dye removal of conventional method is $40.6 \%$ more than the ultrasonic method in the dyeing with C.I. Reactive Blue 4, 38\% more in the ultrasonic method of C.I. Reactive Blue 15 dye, $11.8 \%$ more for C.I. Reactive Blue and 36\% less for C.I. Reactive Blue 69 in the ultrasonic method.
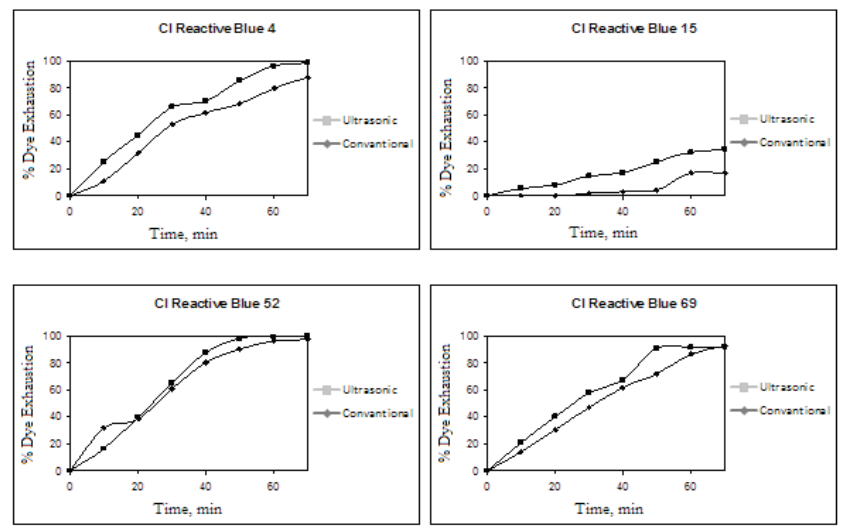

Figure 3. Dye exhaustion rate of the dyes
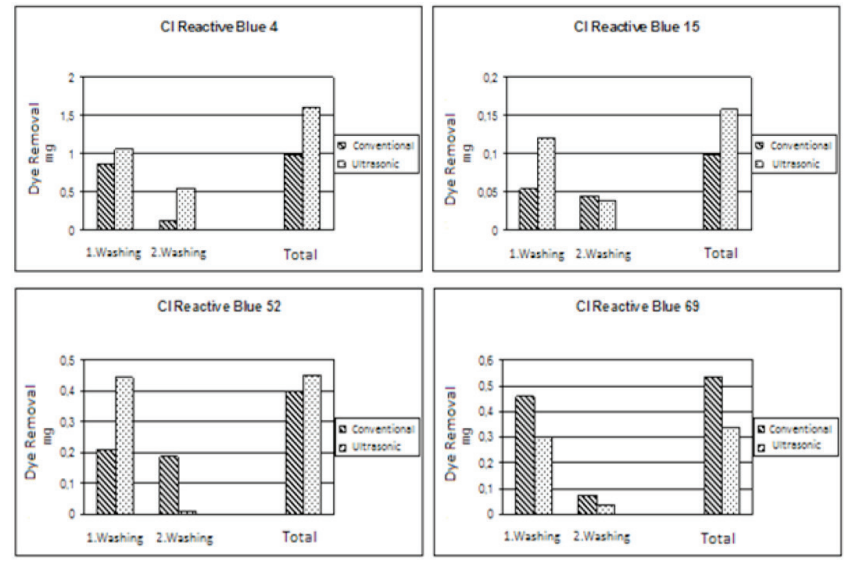

Figure 4. The dye removal after washing 
When the amount of dye was removed after washing process, C.I. Reactive Blue 4 dye was fixed to the fibre becomes $81 \%$ in conventional method and $87 \%$ in ultrasonic method. The dye fixation is $7 \%$ more in the sample that was dyed in accordance with the ultrasonic method.

In the dyeing with C.I. Reactive Blue 15, the dye that was fixed to the fibre becomes $16.4 \%$ in conventional method and $34 \%$ in ultrasonic method. The dye fixation is $51.8 \%$ more in the sample that was dyed in accordance with the ultrasonic method.

When the dye that was removed after the washing. C.I. Reactive Blue 52 fixation is $94.6 \%$ in conventional

method and $96.9 \%$ in ultrasonic method. The dye fixation is $2.3 \%$ more in the sample that was dyed in accordance with the ultrasonic method. In C.I. Reactive Blue 69 dye fixation is $88.9 \%$ with conventional method and $89.8 \%$ with ultrasonic method. The dye fixation is $1 \%$ more in the sample that was dyed in accordance with the ultrasonic method.

\subsection{The Fastness Properties}

When compared with the conventional method, the ultrasonic energy is not much effective in the development of washing, light and rubbing fastness but it is seen to develop perspiration fastness (Table 3).

\subsection{The Colour Measurements}

When the colour measuring values of the samples that were dyed with conventional and ultrasonic methods were analysed in accordance with the CIELab system

(Figure 5), it was determined that the colour of the samples dyed with ultrasonic method has a darker, darker green and darker blue colour shade than the samples that were dyed with conventional method.
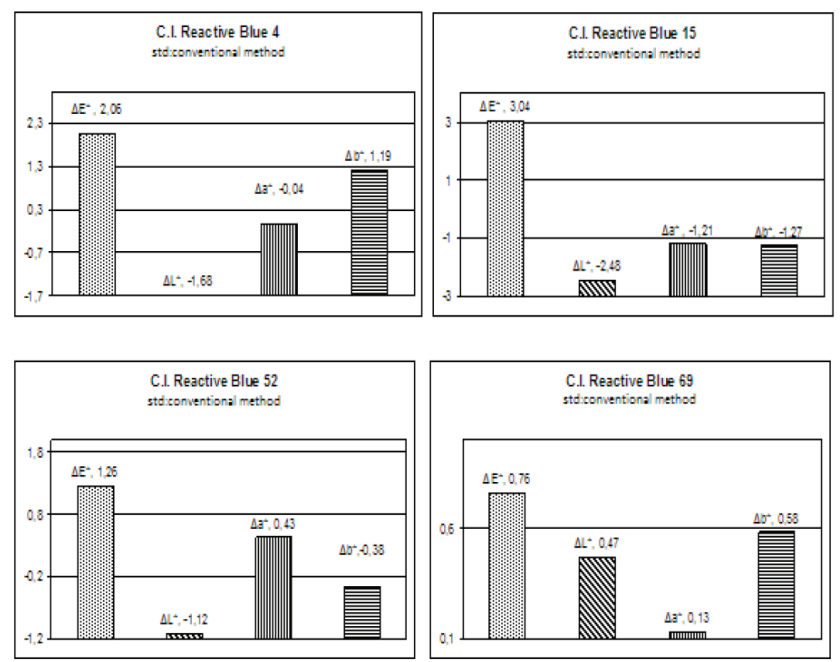

Figure 5. Colour values of the dyeing

Table 3. Fastness values of the dyeing

\begin{tabular}{|c|c|c|c|c|c|c|c|c|c|c|c|c|c|c|c|c|c|c|c|c|c|c|}
\hline \multicolumn{5}{|c|}{ Washing } & \multicolumn{3}{|c|}{ Light } & \multicolumn{5}{|c|}{ Rubbing } & & \multicolumn{9}{|c|}{ Perspiration } \\
\hline \multicolumn{2}{|r|}{$k$} & \multicolumn{3}{|c|}{$u$} & $k$ & & i & \multicolumn{3}{|c|}{$k$} & \multicolumn{2}{|c|}{$u$} & & \multicolumn{5}{|c|}{$k$} & \multicolumn{4}{|c|}{$u$} \\
\hline$r$ & $s$ & & & $s$ & & & & $y$ & & & $y$ & $k$ & & ra & $s a$ & & $r b$ & $s b$ & $r a$ & $s a$ & $r b$ & $s b$ \\
\hline \multicolumn{23}{|c|}{ C.I. Reactive Blue 4} \\
\hline 4 & $4-5$ & & & $4-5$ & 8 & & 7 & 5 & & & 5 & 5 & & 3 & 4 & & 3 & 3 & 5 & 5 & 5 & $4-5$ \\
\hline \multicolumn{23}{|c|}{ C.I. Reactive Blue 15} \\
\hline 5 & 5 & 5 & 5 & 5 & 5 & 5 & 5 & 5 & 5 & 3 & 4 & 3 & 3 & 5 & 5 & 5 & 5 & & & & & \\
\hline \multicolumn{23}{|c|}{ C.I. Reactive Blue 52} \\
\hline 5 & 4 & 5 & 4 & 8 & 8 & 5 & 5 & 5 & 5 & 5 & 5 & 5 & 4 & 5 & 5 & 5 & $4-5$ & & & & & \\
\hline \multicolumn{23}{|c|}{ C.I. Reactive Blue 69} \\
\hline 5 & $4-5$ & 5 & $4-5$ & 8 & 8 & $4-5$ & 5 & 5 & 5 & 4 & 5 & 4 & 5 & 5 & 5 & 4 & 4 & & & & & \\
\hline
\end{tabular}

$k$ : conventional, $u$ : ultrasonic, $r$ : color change, s: fading, $y$ : wet $k$ : dry, $r a$ : colour change acidic, $r b$ : colour change basic, $\mathrm{s} a$ : fading acidic, $s b$ : fading basic 


\section{CONCLUSION}

In this study, where the ultrasonic energy's impact on the dyeing of polyamide material with reactive dyes that include different chromophore and reactive group;

1. In the ultrasonic method, the dye that is transferred to the fibre in proportion to the conventional method is much more in amount. The dye that the ultrasonic energy is the most effective is C.I. Reactive Blue 15. In this dye, compared to the conventional method, $51 \%$ more dye is transferred to the fibre with the ultrasonic method.

2. During the washings after dyeing the most transferred dye in the washing solution is C.I. Reactive Blue 4. This value is $40.6 \%$ more than the ultrasonic dyed sample.

3. The amount of dyes that is fixed to the fibre in all blue dyes is more in ultrasonic method. The most effective dyes in terms of colour fixation of the ultrasonic impact is C.I. Reactive Blue 15 and it becomes $16.4 \%$ in conventional method and $34 \%$ in ultrasonic method. The dye fixation is $51.8 \%$ more in the sample that is coloured in accordance with the ultrasonic method.

4. It is seen that the ultrasonic energy is not much effective in the development of washing, light and rubbing fastness of the dyeing, but it develops perspiration fastness.

5. It is determined that the colour of the samples that were dyed with ultrasonic method has a darker, darker green and darker blue colour compared to the samples dyed with conventional method.

\section{REFERENCES}

[1] Mason,T.J, Lormier,J.P. (1988).Sonochemistry: Theory, Applications and Uses of Ultrasound in Chemistry. Ellis Horwood Limited.

[2] Duran K., Bahtiyari M.İ., Körlü A.E., Dereli S., Özdemir D. (2006), Ultrasound Technology, Tekstil ve
Konfeksiyon, 3,155:162-166.

[3] Perincek S., Uzgur E., Duran K., Doğan A., Körlü A., Bahtiyari İ., (2009), Design parameter investigation of industrial size ultrasound textile treatment bath. Ultrasonics Sonochemistry. 16:184-189

[4] Akalın, M., Merdan, N., Koçak, D. Usta, I. , (2004), Effects of ultrasonic energy on the wash fastness of reactive dyes,Ultrasonics. 42:161-164.

[5] Öner, E., Başer, İ., Acar, K., (2004). Use of ultrasonic energy in reactive dyeing cellulosic fabrics, JSDC., 11: 279-281.

[6] Sun, D., Guo, O., and Liu, X.. (2010). Investigation into dyeing acceleration efficiency of ultrasound energy, Ultrasonics.50:441-446.

[7] Lee, K.W., Chung, Y.S., and Kim, J.P., (2003), Characteristics of Ultrasonic Dyeing on Poly(ethylene Terephthalate). Textile Research Journal. 73: pp.751755 .

[8] Merdan, N., Akalın, M., Kocak, D., Usta, I., (2004), Effects of ultrasonic energy on dyeing of polyamide (microfibre)/Lycra blends. Ultrasonics, 42:165-168.

[9] Shore,J., Cellulosing Dyeing, Society Dyers and Colorists, (1995).

[10] Lewis, D., (ed) (1992). Wool Dyeing, Society of Dyers and Colorists.

[11] Giles, C.H., (1974). A Laboratory Course of Dyeing, The Society of Dyers and Colourists.

[12] Thakore, K., A., Smith, C., B., (1999). Application of Ultrasound to Textile Wet Processing, American Dyestuff Reporter.45-47.

[13] Bird, C.L. (Ed.), Boston, W.S. (Ed.),( 1975). The Theory of Coloration of The Textile, The Dyers Comp. Pub. Trust . 